\title{
Predictors of mothers' postpartum body dissatisfaction based on demographic and fertility factors
}

\author{
Mehrri Tavakoli, Seyedeh Batool Hasanpoor-Azghady * (D) and Leila Amiri Farahani
}

\begin{abstract}
Background: There are fundamental and rapid changes in body shape during pregnancy, some of which persist for an extended time after delivery and may cause dissatisfaction with body shape. Therefore, we conducted this study to determine predictors of body dissatisfaction at six months postpartum based on demographic and fertility factors.
\end{abstract}

Methods: This cross-sectional study was conducted on 300 women who referred to seven health centers affiliated with Iran University of Medical Sciences, Tehran, Iran. The sampling was multistage and we collected data from a demographic and fertility questionnaire and Cooper's Body Shape Questionnaire (BSQ-34). The independent t-test, Mann-Whitney $U$ test, chi-square test, one-way ANOVA, Kruskal-Wallis, Pearson correlation coefficient, and multiple linear regression were used for data analysis. The level of significance was set at $P<0.05$.

Results: The mean age of participating women was 29.77 (standard deviation: 5.9) years. Body dissatisfaction had a statistically significant association with variables such as body mass index (BMI) at six months postpartum, gestational age, the receipt of information about body shape, spouse's views on the shape of a woman's body, and mode of delivery. These variables predicted 34\% of body dissatisfaction based on multiple linear regression.

Conclusion: Postpartum body dissatisfaction is related to a several variables. Paying attention to these variables will help to plan and improve postpartum counseling and educational programs.

Keywords: Body dissatisfaction, Postpartum, Body image, Demographic factors, Fertility factors

\section{Background}

In today's society, there is tremendous emphasis on physical attractiveness and fitness. Social pressures on women to have a slim body and meet the standards of beauty have increased women's dissatisfaction with their physical appearance [1]. During pregnancy, there are fundamental and rapid changes in a woman's body shape and weight. Some changes begin far before a woman is aware of her pregnancy [2]. Society expects women to

\footnotetext{
* Correspondence: hasanpoorbatool@yahoo.com

Department of Midwifery and Reproductive, Nursing Care Research Center (NCRC), School of Nursing and Midwifery, Iran University of Medical Sciences, Rashid Yasemi st., Valiasr St, Tehran 1996713883, Iran
}

control their weight after child birth, which is stressful [3]. Longitudinal studies that examine body image during pregnancy show that although pregnant women may have a period of relative satisfaction about their body image during mid- to late pregnancy, worrying about it may peak after delivery [3-5]. Overall, all prospective studies that have investigated the effect of body image on postpartum depression found a positive association between body dissatisfaction and postpartum depression at different time periods, up to 12 months after delivery $[1,6]$. In pregnancy, women tolerate body changes (e.g., large abdomen, swollen feet, weight gain) because they perceive the positive function of these changes [3];

C C The Author(s). 2021 Open Access This article is licensed under a Creative Commons Attribution 4.0 International License, which permits use, sharing, adaptation, distribution and reproduction in any medium or format, as long as you give appropriate credit to the original author(s) and the source, provide a link to the Creative Commons licence, and indicate if changes were made. The images or other third party material in this article are included in the article's Creative Commons licence, unless indicated otherwise in a credit line to the material. If material is not included in the article's Creative Commons licence and your intended use is not permitted by statutory regulation or exceeds the permitted use, you will need to obtain permission directly from the copyright holder. To view a copy of this licence, visit http://creativecommons.org/licenses/by/4.0/ The Creative Commons Public Domain Dedication waiver (http://creativecommons.org/publicdomain/zero/1.0/) applies to the data made available in this article, unless otherwise stated in a credit line to the data. 
however, body dissatisfaction is reported by many women during the postpartum period [7].

The results of a systematic review showed that women who had better body image were more likely to breastfeed [8] and that women who breastfeed have a stronger relationship with their infants [9]. On the other hand, women who were more concerned about their bodies were less likely to breastfeed or stopped breastfeeding earlier [8]. Some women stopped breastfeeding because of their disgust with breast shape after giving birth [10]. Body dissatisfaction has also been reported to reduce sexual satisfaction [11]. Swedish women often found it difficult to adapt to physical changes and expressed discontent with the looseness of their genitals and the size of their breasts [12]. The reactions to such changes depend on a variety of factors, including cultural and family attitudes, social factors such as visual media, and social normative pressures, standards, and definitions of social beauty [13].

Among the body image factors reported during the postpartum period, younger women were reported to have more body satisfaction than older women because they had lower weight and fewer children, and paid more attention to themselves [14]. Body image satisfaction was also associated with college education, employment, regular exercise, receipt of postpartum information, childcare assistance, the presence of a positive attitude about oneself, and the husband's positive attitude towards his wife [14].

The results of studies showed different findings on women's attitudes towards their postpartum body image. In one study, mothers from Minnesota (USA) reported that body dissatisfaction escalated from one to nine months after childbirth [15]. Erbil et al. [14] also reported that $42.3 \%$ of Turkish women had a negative attitude about their body size. However, $57 \%$ of African-American women had a positive attitude about their body size after childbirth and $79.1 \%$ said that their spouses also had a positive attitude towards their body size [4].

Although there are physiological changes that occur during pregnancy and the postpartum period that put women under sociocultural pressures [3, 4], only a few studies have used a qualitative approach to assess postpartum body dissatisfaction [1]. To date, no studies have assessed postpartum body dissatisfaction among Iranian women; therefore, we conducted this study to determine predictors of body dissatisfaction based on demographic and fertility factors at six months postpartum in Iranian women.

\section{Methods}

This cross-sectional study enrolled 300 women, six months after childbirth, from seven health centers affiliated with Iran University of Medical Sciences. The university covers seven districts in Tehran (the capital of
Iran). The sampling was multi-stage. First, a health center was randomly selected from each district and we determined the number of eligible individuals as a quota from this center. Next, continuous sampling was conducted at each center between May 2018 and January 2019. The inclusion criteria for study participation consisted of the ability to read and write, lack of stressful events in the previous six months, no use of drugs or any medications related to mental disorders, lack of chronic systemic disease in the mother, lack of high-risk pregnancy (except for premature labor), lack of abnormality in the child, no specific postpartum diet, and no postpartum abdominal cosmetic surgery.

We used $G$ * power software to determine the required sample size. Sample size at $95 \%$ confidence level with test power of 0.9, effect size medium level based on Cohen's classification and considering that the number of predictor variables was 19 of variables, was calculated to be 272 people, which in this study we considered 300 people.

Data collection tools included a demographic and fertility questionnaire and the Persian version of the 34item Body Shape Questionnaire (BSQ-34). The BSQ-34 was developed by Cooper et al. in 1987. The BSQ-34 measures concerns about body shape and has been used to assess body dissatisfaction [16]. Each item is measured with a six-point Likert scale, as follows: 1 (never), 2 (rarely), 3 (sometimes), 4 (often), 5 (very often), and 6 (always). The score of the items ranges from 34 to 204 . A higher score indicates greater dissatisfaction with body shape [16].

In the Rosen et al. study [17], the reliability of Cooper's body shape questionnaire was reported as 0.88 using the test-retest method. According to Evans and Dolan [18], the internal consistency of the questionnaire was confirmed by a Cronbach's alpha value of $0.97 \%$. In Iran, Sadeghi et al. reported a Cronbach's alpha value of $0.95 \%$ and test-retest of 0.82 [19].

We initiated sampling at the health centers after receipt of study approval by the Ethics Committee of Iran University of Medical Sciences (code: IR.IUMS.REC 1395. 9,311,373,008). The participants provided written informed consent for study participation. Next, participants completed the self-administered questionnaires. Data were analyzed using the independent t-test, MannWhitney U test, one-way ANOVA, Kruskal-Wallis, Pearson correlation, and multiple linear regression using SPSS version 21. The multiple linear regression model was used to determine the simultaneous effect of the variables, each of which was related to the dependent variable using the Enter method. Before implementation of multivariate analysis, we checked the regression assumptions, such as normality of the residuals, homoscedasticity, multicollinearity, and independence of the residuals. The significance level for all tests was $p<0.05$. 


\section{Results}

According to the results, participants had a mean $[ \pm \mathrm{SD}]$ age of $29.77[ \pm 5.9]$ years. Mean $[ \pm S D]$ weight before pregnancy was $62.35[ \pm 10.81] \mathrm{kg}$ and six months postpartum was $66.95[ \pm 11.54] \mathrm{kg}$. Also, participants had a mean $[ \pm \mathrm{SD}] \mathrm{BMI}$ of $23.91[ \pm 4.1]$ before pregnancy and $25.69[ \pm 4.52]$ six months postpartum. Most subjects had a college education (49.7\%) and a relatively favorable economic status (62.7\%). A total of $62 \%$ of participants were primipara. Table 1 provides additional demographic information and fertility characteristics of the participants.

Pearson correlation coefficient showed that body dissatisfaction had a directly significant relationship with BMI at six months postpartum $(p<0.001 ; \mathrm{r}=0.45)$. But there was no relationship between body dissatisfaction with women's age $(P=0.80 ; \mathrm{r}=-0.14)$. Tables 2 and 3 show the relationship between other demographic and fertility variables with body dissatisfaction score.

We placed the participants in the two groups of normal BMI and high BMI. The chi-square test results showed that there was no statistically significant difference between the two groups of normal BMI and high BMI in terms of receipt of information about body shape $(p=0.84)$.

An examination of the one-to-one relationship of variables to body dissatisfaction indicated a statistically significant relationship between variables, which included BMI at six months postpartum, gestational age, receipt of information about body shape, spouse's views on the shape of a woman's body, and the mode of delivery. These variables were entered into the multiple linear regression model using the Enter method and they could remain within the model. According to the results, the mean score for body dissatisfaction of women at six months postpartum for each unit added to the BMI increased by 2.52 units; however, this amount decreased by 8.08 units in women with NVD compared to women who underwent cesarean section. The mean score for body dissatisfaction among subjects who gave birth to term infants decreased by 15.28 units compared to those who gave birth to preterm infants. This score increased by 8.77 units in subjects who received body shape information compared to those who did not receive any information. Furthermore, from the spouse's view on the shape of a woman's body, the mean score of body dissatisfaction in women whose spouses were somewhat satisfied with their body shape was 14.54 units higher than those whose spouses were very satisfied with their body shape. In women whose spouses were indifferent to their body shape, the mean score was 23.6 units higher than women whose spouses were very satisfied with their body shape. In women whose spouses were somewhat dissatisfied with their body shape, the mean body dissatisfaction score was 28.62 units higher than women whose spouses were very satisfied with their body shape, while in women whose spouses were very dissatisfied with their body shape, the mean body dissatisfaction score was 41.60 units higher than the women whose spouses were very satisfied with their body shape.

Therefore, based on the results, 34\% of changes in dependent variables (body dissatisfaction at six months postpartum) were explained by independent variables that included BMI at six months postpartum, gestational age, receipt of information about body shape, spouse's views on the shape of a woman's body, and the mode of delivery. Among these variables, the six-month postpartum, BMI was the most effective predictor of postpartum dissatisfaction (Table 4).

\section{Discussion}

The present study aimed to determine the predictors of body dissatisfaction at six months postpartum based on demographic and fertility characteristics. The results showed that body dissatisfaction had a significant relationship with variables such as BMI at six months postpartum, gestational age, receipt of information about body shape, spouse's views on the shape of a woman's body, and mode of delivery. Among these variables, the six-month postpartum BMI was the most effective predictor of postpartum body dissatisfaction. The higher the BMI, the greater the dissatisfaction. In this respect, the results of a study by Gjerdingen et al. indicated that an elevated BMI was the most important factor associated with body dissatisfaction [15]. Evidence suggests that increased attention to appearance, especially postpartum weight and obesity, results in increased body dissatisfaction among women [20]. The target weight of some women after childbirth is even lower than the prepregnancy weight, which results in increased body dissatisfaction [21]. Our study subjects weighed a mean of $4.600 \mathrm{~kg}$ more than their pre-pregnancy weights in the six months following delivery. Participants in the study by Gjerdingen et al. weighed $2.5 \mathrm{~kg}$ more in the nine months following delivery than before pregnancy [15]. Since the timing of these two studies is different, it is not possible to compare postpartum weight retention; however, in a study conducted by Rallis et al., it has been shown that dissatisfaction with body shape was most prevalent in the six months following delivery. In the study mentioned above, the mean BMI six months after delivery was 24.90; in the current study, it was 25.69, which could be attributed to the large sample size of the current study [5]. The results of another study showed that most participants described body changes during pregnancy with one objective and meaning. In their opinion, the unique event of becoming a mother enabled women to deal positively with changes in their bodies 
Table 1 Demographic and fertility characteristics in women six months postpartum $(n=300)$

\begin{tabular}{|c|c|c|c|}
\hline Characteristics & $\mathrm{N}(\%)$ & Characteristics & $\mathrm{N}(\%)$ \\
\hline Woman's education & & Preterm & $19(6.3)$ \\
\hline$<$ High school & $55(18.3)$ & Breastfeeding period & \\
\hline High school & $96(32)$ & $<6$ Months & $35(11.7)$ \\
\hline Academic & $149(49.7)$ & 6 Months & $265(88.3)$ \\
\hline Spousal's education & & Nutrition status of the in & \\
\hline$<$ High school & $58(19.3)$ & Breast-feeding & $213(71)$ \\
\hline High school & $109(36.3)$ & Bottle-feeding & $36(12)$ \\
\hline Academic & $133(44.3)$ & Both & $51(17)$ \\
\hline Birthplace & & Receiving information a & \\
\hline Urban & $222(74)$ & yes & $94(31.3)$ \\
\hline Rural & $78(26)$ & No & $206(68.7)$ \\
\hline Woman's occupation & & Spouse's views on the $s$ & \\
\hline Housewife & $231(77)$ & Very satisfied & $97(32.3)$ \\
\hline Employed & $69(23)$ & Somewhat satisfied & $138(46)$ \\
\hline Spousal's occupation & & Indifferent & $37(12.3)$ \\
\hline Employee & $105(35)$ & Somewhat dissatisfied & $21(7)$ \\
\hline Free & $148(49.3)$ & Very dissatisfied & $7(2.3)$ \\
\hline Worker & $38(12.7)$ & livery & \\
\hline
\end{tabular}

Unemployed

Economic status

Favorable

Relatively favorable

Undesirable

Infertility history

Yes

$20(6.7)$

No

280 (93.3)

Abortion history

Yes

54 (18)

No

$246(82)$

Mode of delivery

${ }^{\mathrm{a} N V D}$

139 (46.3)

${ }^{b} \mathrm{C} / \mathrm{S}$

Parity

Primipara

Multipara

$114(38)$

Pregnancy

Wanted

Unwanted

$19(6.3)$

Wanted and unwanted baby's gender

Wanted

Unwanted

Gestational age
Table 1 Demographic and fertility characteristics in women six months postpartum $(n=300)$ (Continued)

${ }^{\mathrm{b}}$ Caesarean section

during pregnancy. Society also has a positive interpretation of pregnancy changes, but dissatisfaction and striving to reclaim the postpartum body dominated [22].

In the present study, there was no relationship between women's age, the woman and her husband's level of education, the woman and her husband's job, and economic status with body dissatisfaction. Although body dissatisfaction in women whose husbands were workers was less than women whose husbands were employees, this difference was not statistically significant. In this respect, Gjerdingen et al. [15] reported that woman's age, education, income, health insurance, and their employment status were not related to body shape dissatisfaction. It has also been noted that the relative importance of social factors regarding postpartum body dissatisfaction is uncertain and not well-studied. In another study, the results showed no relationship between age, job, and education with body shape dissatisfaction [23].

The results reported by Walker et al. on the relationship between dissatisfaction with body shape and race showed that black women were more satisfied with their body shape than white women [24]. In the current study, all subjects were of the same race; therefore, we compared body shape dissatisfaction between women in urban versus rural areas. In terms of socio-economic factors, just as blacks in most parts of the world are at a lower socioeconomic level than whites, village residents have a lower socioeconomic status than urban residents. 
Table 2 The relationship between demographic characteristics and body dissatisfaction score in women six months postpartum $(n=300)$

\begin{tabular}{|c|c|c|}
\hline Characteristics & Mean (SD) & $P$-value \\
\hline \multicolumn{3}{|l|}{ Woman's education } \\
\hline$<$ High school & $74.29(32.43)$ & $0.832^{*}$ \\
\hline High school & $73.48(33.62)$ & \\
\hline Academic & 76.07 (34.01) & \\
\hline \multicolumn{3}{|l|}{ Spousal's education } \\
\hline$<$ High school & $76.91(32.94)$ & $0.587^{*}$ \\
\hline High school & 72.28 (29.99) & \\
\hline Academic & $76.2(36.48)$ & \\
\hline \multicolumn{3}{|l|}{ Birthplace } \\
\hline Urban & 77.70 (33.89) & $0.281^{* *}$ \\
\hline Rural & $66.99(31.30)$ & \\
\hline \multicolumn{3}{|l|}{ Woman's occupation } \\
\hline Housewife & $73.41(34.90)$ & $0.273^{* *}$ \\
\hline Employed & $79.96(31.23)$ & \\
\hline \multicolumn{3}{|l|}{ Spousal's occupation } \\
\hline Employee & $79.03(37.42)$ & $0.389^{* * *}$ \\
\hline Free & $74.16(31.75)$ & \\
\hline worker & $65.47(25.83)$ & \\
\hline Unemployed & $79.11(38.59)$ & \\
\hline \multicolumn{3}{|l|}{ Economic status } \\
\hline Favorable & 73.80 (32.59) & $0.372^{* * *}$ \\
\hline Relatively favorable & 76.69 (34.60) & \\
\hline Undesirable & $63.31(25.23)$ & \\
\hline
\end{tabular}

Our findings showed that body dissatisfaction among women born in a village was lower than among those born in a city. This was not a statistically significant difference, as rural-born women made up a quarter of the subjects in our study. However, another explanation for decreased body dissatisfaction among rural women might be that they are less exposed to receipt of information, social pressures, and media publicity.

The results of the present study show that body dissatisfaction is related to the views of the spouse on the shape of the woman's body. Women whose spouses were very satisfied with their body shape expressed higher body satisfaction. In this regard, the results of another study showed that a negative assessment by the spouse was strongly related to body dissatisfaction and, after the weight variable, the history of negative encounters in the family was of tremendous importance in terms of dissatisfaction with the shape of the body [25]. In the postpartum period, spouses play a major role in supporting women by providing positive feedback on the physical changes of the woman's body [21]. Mickelson et al.
Table 3 The relationship between fertility characteristics and body dissatisfaction score in women six months postpartum $(n=300)$

\begin{tabular}{|c|c|c|}
\hline Characteristics & Mean (SD) & $P$-value \\
\hline \multicolumn{3}{|l|}{ Infertility history } \\
\hline Yes & $76.50(33.53)$ & $0.795^{*}$ \\
\hline No & $74.80(33.57)$ & \\
\hline \multicolumn{3}{|l|}{ Abortion history } \\
\hline Yes & $82.59(32.36)$ & $0.061^{* *}$ \\
\hline No & $73.23(33.59)$ & \\
\hline \multicolumn{3}{|l|}{ Mode of delivery } \\
\hline${ }^{c} \mathrm{NVD}$ & $69.45(28.28)$ & $0.007^{* *}$ \\
\hline${ }^{d} C / S$ & $79.63(36.89)$ & \\
\hline \multicolumn{3}{|l|}{ Parity } \\
\hline Primipara & $74.40(34.56)$ & $0.731^{* *}$ \\
\hline Multipara & $75.75(31.87)$ & \\
\hline \multicolumn{3}{|l|}{ Pregnancy } \\
\hline Wanted & $74.53(33.49)$ & $0.158^{*}$ \\
\hline Unwanted & $80.63(33.21)$ & \\
\hline \multicolumn{3}{|c|}{ Wanted and unwanted baby's gender } \\
\hline Wanted & $74.16(33.29)$ & $0.504^{* *}$ \\
\hline Unwanted & $77.16(34.21)$ & \\
\hline \multicolumn{3}{|l|}{ Gestational age } \\
\hline Term & $73.61(32.59)$ & $0.029^{*}$ \\
\hline Preterm & $94.21(41.40)$ & \\
\hline \multicolumn{3}{|l|}{ Breastfeeding period } \\
\hline$<6$ Months & $80.23(40.81)$ & $0.401^{* *}$ \\
\hline 6 Months & $74.21(32.46)$ & \\
\hline \multicolumn{3}{|c|}{ Nutrition status of the infant } \\
\hline Breast-feeding & $72.01(30.96)$ & $0.081^{* * *}$ \\
\hline Bottle-feeding & $88.89(42.96)$ & \\
\hline Both & $77.18(34.31)$ & \\
\hline \multicolumn{3}{|c|}{ Receiving information about the body shape } \\
\hline yes & $83.38(36.19)$ & $0.003^{* *}$ \\
\hline No & $71.05(31.56)$ & \\
\hline \multicolumn{3}{|c|}{ Spouse's views on the shape of a woman's body } \\
\hline Very satisfied & $56.34(24.15)$ & $<0.001^{* * *}$ \\
\hline Somewhat satisfied & $79.78(30.74)$ & \\
\hline Indifferent & $86.73(35.60)$ & \\
\hline Somewhat dissatisfied & $93.76(35.73)$ & \\
\hline Very dissatisfied & $117.43(53.62)$ & \\
\hline
\end{tabular}

concluded that maternal satisfaction with body shape after childbirth was accepted only with the consent of the spouse and it was indirectly related to the satisfaction of 
Table 4 Results of multiple linear regression analysis to investigate the effect of demographic and fertility characteristics on physical satisfaction

\begin{tabular}{|c|c|c|c|c|c|c|c|}
\hline Independent variable & & B Coefficient & $\begin{array}{l}\text { Standardized } \\
\text { Coefficient }\end{array}$ & Statistics & P-value & $95 \% \mathrm{Cl}(\mathrm{L} / \mathrm{H})$ & R2 \\
\hline BMI six months postpartum & & 2.52 & 0.34 & 6.72 & $<0.001$ & $1.78 / 3.26$ & 0.34 \\
\hline \multirow[t]{2}{*}{ Mode of delivery } & ${ }^{\mathrm{e}} \mathrm{C} / \mathrm{S}$ & \multicolumn{6}{|c|}{ Reference Category } \\
\hline & ${ }^{f} \mathrm{NVD}$ & -8.08 & -0.12 & -2.49 & 0.013 & $-14.47 /-1.69$ & \\
\hline \multirow[t]{2}{*}{ Gestational age } & Preterm & \multicolumn{6}{|c|}{ Reference Category } \\
\hline & Term & -15.28 & -0.11 & -2.32 & 0.021 & $-28.24 /-2.32$ & \\
\hline \multirow[t]{2}{*}{ Receiving information about the body shape } & No & \multicolumn{6}{|c|}{ Reference Category } \\
\hline & Yes & 8.77 & 0.12 & 2.52 & 0.012 & $1.93 / 15.61$ & \\
\hline \multirow[t]{5}{*}{ Spouse's views on the shape of a woman's body } & Very satisfied & \multicolumn{6}{|c|}{ Reference Category } \\
\hline & Somewhat satisfied & 14.54 & .21 & 3.79 & $<0.001$ & $6.99 / 22.09$ & \\
\hline & Indifferent & 23.6 & 0.23 & 4.31 & $<0.001$ & $12.83 / 34.37$ & \\
\hline & Somewhat dissatisfied & 28.62 & 0.21 & 4.21 & $<0.001$ & $15.24 / 41.99$ & \\
\hline & Very dissatisfied & 41.60 & 0.18 & 3.75 & $<0.001$ & $19.78 / 63.42$ & \\
\hline
\end{tabular}

${ }^{\mathrm{e}}$ Cesarean Section

${ }^{f}$ Normal Vaginal Delivery

their private affairs. In other words, mothers understand that their spouses do not accept them in sexual relations, making them less satisfied with their private lives. Researchers in this study reported a clear link between body shape dissatisfaction and intimate relationships. Postpartum intimacy for a woman might be related to her husband's satisfaction with the shape of her body [26].

Our study found that women with less information about body shape were more satisfied with their body shape. Information coupled with cultural and social pressures may make women feel unattractive, dissatisfied with their body, anxious, depressed, and stressed [4]. Most of the women's self-consciousness with their bodies is rooted in the image of a beautiful body created by society. This self-consciousness and monitoring of the body as an item for assessment by others leads to increased body dissatisfaction [27]. By promoting a thin body as a beauty criterion, the media also causes women to experience unrealistic postpartum pressure on their body shape, and makes them want to quickly lose the weight they gained during pregnancy [21].

The present research showed a significant association between body dissatisfaction and the mode of delivery (NVD, cesarean section). In a qualitative study, Berry indicated that in women during five weeks after cesarean section, factors such as wound repair, therapeutic interventions such as injections and insertion of intravenous lines, digestive and nutritional problems, movements needed to breastfeed the baby, and reduced body function caused them to feel dissatisfied with their body image [28]. In our study, there was no association between body dissatisfaction with parity (multipara and primipara), abortion, infertility history, wanted and unwanted pregnancy, and baby's gender. Gjerdingen et al. also reported that variables such as the baby's gender were not related to body shape dissatisfaction after delivery [15]. In line with our study, there was no significant difference in body image between multiparous and primiparous women in other studies conducted in Iran [29]. The findings of the study by Rahmanian et al. also showed that there was no association between wanted and unwanted pregnancy and dissatisfaction with body shape; however, parity was related to body dissatisfaction. Because multiparous women have experienced pregnancy and are aware of changes in body shape during this period, they know which physical changes are reversible and which are permanent; therefore, multiparous women are more dissatisfied with their body shape than primiparous women who see pregnancy and its changes as a motherhood experience [23].

In our study, there was a statistically significant difference in the mean score of body dissatisfaction ( $p=$ 0.009), which depended on gestational age. Mothers who gave birth to preterm infants were more dissatisfied with their body shape. The researcher did not find a comparative study in this regard. In the current study, we observed no relationship between body satisfaction of mothers with different feeding conditions for infants (breast milk, bottle-feeding, both) and the duration of breastfeeding, which contradicted the results from other studies. The results of these studies have indicated that dissatisfaction with body shape affects breastfeeding self-efficacy, reduces the tendency to breast-feed, and causes women to stop breastfeeding earlier $[8,10,20]$. 
There were a number Strengths and limitations to this study. One of the strengths of this study is that we considered the variable of the spouse's views on the shape of a woman's body. According to Duncombe et al., women who had a positive attitude towards their bodies after childbirth often stated that their spouses also had a positive attitude about their body size [4]. Another strength is that in the present study, we examined the association of body dissatisfaction with receiving information about body shape. The results showed participants who received information were more dissatisfied about their body shape. We also examined the role of $\mathrm{BMI}$ as an intervening variable in this regard. T-test showed that there was no statistically significant difference in mean BMI in terms of receiving information about body shape.

The study had several limitations. Because the data were based on self-reported answers by the subjects, the response to some items might have been influenced by cultural factors and society values. A major difficulty we encountered in data analysis was how to score the BSQ34. There was no difference between worry about body shape and its absence. Cooper et al. did not determine the cut-off point for the questionnaire. Although we observed no relationship between participants' education and body shape dissatisfaction, education might have influenced the relationship between other variables and body shape dissatisfaction. Approximately 50\% of the participants in our study had a college education; therefore, the generalization of the results of the present study might be less for studies where participants have lower educational levels. Finally, the assessment of body dissatisfaction was limited to just six months postpartum.

\section{Conclusion}

The results showed a relationship between body dissatisfaction and several variables. The BMI at six months postpartum had the greatest effect on body dissatisfaction. Paying attention to weight and the other variables can help clinicians prepare and develop counseling or education programs for women to gain proper weight during pregnancy and have proper diet and postpartum activities.

\section{Abbreviations}

BSQ: Body Shape Questionnaire; BMI: Body Mass Index; NVD: Normal Vaginal Delivery; IV line: Intravenous Line

\section{Acknowledgments}

We would like to express our sincere gratitude and appreciation from the honorable authorities of Iran University of Medical Sciences to the dear staff of health centers, and dear mothers for their cooperation with the research team.

\section{Authors' contributions}

M.T and SBHA designed the study. M.T collected data. M.T, SBHA, and L.A.F analyzed and interpreted the data. Moreover, SBHA and L.A.F wrote and revised the paper. All of the authors read and approved the final manuscript.

\section{Funding}

The present study is the result of a master's thesis funded by the Research Deputy of Iran University of Medical Sciences, Tehran, Iran.

\section{Availability of data and materials}

The datasets used and analyzed during the current study are available from the corresponding author on reasonable request.

\section{Ethics approval and consent to participate}

The research project was confirmed by the Ethics Committee of Iran University of Medical Sciences, Tehran, Iran, with the ethics code of IR.IUMS.REC 1395. 9311373008. After obtaining a sampling license from Iran University of Medical Sciences. The participants were asked to sign a written informed consent. Respondents were completely informed of the study purpose and procedures. Besides, they were assured of the confidentiality of information.

\section{Consent for publication}

Not applicable.

\section{Competing interests}

The authors declare that they have no competing interests.

Received: 25 April 2020 Accepted: 16 December 2020

Published online: 05 January 2021

\section{References}

1. Silveira ML, Ertel KA, Dole N, Chasan-Taber L. The role of body image in prenatal and postpartum depression: a critical review of the literature. Arch Womens Ment Health. 2015;18:409-21.

2. Watson B, Fuller-Tyszkiewicz M, Broadbent J, Skouteris $H$. The meaning of body image experiences during the perinatal period: a systematic review of the qualitative literature. Body image. 2015;14:102-13.

3. Clark A, Skouteris H, Wertheim EH, Paxton SJ, Milgrom J. The relationship between depression and body dissatisfaction across pregnancy and the postpartum a prospective study. J Health Psychol. 2009;14:27-35.

4. Duncombe D, Wertheim EH, Skouteris H, Paxton SJ, Kelly L. How well do women adapt to changes in their body size and shape across the course of pregnancy? J Health Psychol. 2008;13:503-15.

5. Rallis S, Skouteris H, Wertheim EH, Paxton SJ. Predictors of body image during the first year postpartum: a prospective study. Women \& health. 2007:45:87-104.

6. Riquin E, Lamas C, Nicolas I, Lebigre CD, Curt F, Cohen H, Legendre G, Corcos M, Godart N. A key for perinatal depression early diagnosis: the body dissatisfaction. J Affect Disord. 2019;15(245):340-7.

7. Shloim N, Rudolf M, Feltbower R, Hetherington M. Adjusting to motherhood. The importance of BMI in predicting maternal well-being, eating behaviour and feeding practice within a cross cultural setting. Appetite. 2014;81:261-8.

8. Morley-Hewitt AG, Owen AL. A systematic review examining the association between female body image and the intention, initiation and duration of post-partum infant feeding methods (breastfeeding vs bottle-feeding). J Health Psychol. 2019. https://doi.org/10.1177/1359105319833744.

9. Hilson JA, Rasmussen KM, Kjolhede CL. High prepregnant body mass index is associated with poor lactation outcomes among white, rural women independent of psychosocial and demographic correlates. J Hum Lact. 2004;20:18-29.

10. Brown H, Randle J. Living with a stoma: a review of the literature. J Clin Nurs. 2005;14:74-81.

11. Ogle JP, Tyner KE, Schofield-Tomschin S. Jointly navigating the reclamation of the "woman I used to be": negotiating concerns about the postpartum body within the marital dyad. Clothing Textiles Res J. 2011;29:35-51.

12. Olsson A, Lundqvist M, Faxelid E, Nissen E. Women's thoughts about sexual life after childbirth: focus group discussions with women after childbirth. Scand J Caring Sci. 2005;19:381-7.

13. Danielsson AJ, Hasserius R, Ohlin A, Nachemson AL. Body appearance and quality of life in adult patients with adolescent idiopathic scoliosis treated with a brace or under observation alone during adolescence. Spine. 2012; $37: 755-62$. 
14. Erbil N, Şenkul A, Başara GF, Sağlam Y, Gezer M. Body image among Turkish women during the first year postpartum. Health Care Women Int. 2012;33: 125-37.

15. Gjerdingen D, Fontaine P, Crow S, McGovern P, Center B, Miner M. Predictors of mothers' postpartum body dissatisfaction. Women \& health. 2009:49:491-504.

16. Cooper PJ, Taylor MJ, Cooper Z, Fairbum CG. The development and validation of the body shape questionnaire. Int J Eat Disord. 1987;6:485-94

17. Rosen JC, Jones A, Ramirez E, Waxman S. Body shape questionnaire: studies of validity and reliability. Int J Eat Disord. 1996;20:315-9.

18. Evans C, Dolan B. Body shape questionnaire: derivation of shortened "alternate forms". Int J Eat Disord. 1993;13:315-21.

19. Sadeghi K, Rezaei M, Veisy F, Raeesi F, Shahverdi J. Psychometric properties of the 34-item body shape questionnaire in students. J Kermanshah University Med Sci. 2014;18:316-22.

20. Rodgers RF, O'Flynn JL, Bourdeau A, Zimmerman E. A biopsychosocial model of body image, disordered eating, and breastfeeding among postpartum women. Appetite. 2018;126:163-8.

21. Lovering ME, Rodgers RF, George JE, Franko DL. Exploring the tripartite influence model of body dissatisfaction in postpartum women. Body image. 2018;24:44-54.

22. Hodgkinson EL, Smith DM, Wittkowski A. Women's experiences of their pregnancy and postpartum body image: a systematic review and metasynthesis. BMC pregnancy childbirth. 2014;1:14-330.

23. Rahmanian V, Zolala F, Mohseni M, Baneshi M, KHalili N. Relationship between body image and social participation in pregnant women of Jahrom City, Iran. Horizon Med Sci. 2017;23:111-6.

24. Walker LO. Weight-related distress in the early months after childbirth. West J Nurs Res. 1998;20:30-44.

25. Thornton PL, Kieffer EC, Salabarría-Peña Y, Odoms-Young A, Willis SK, Kim H, et al. Weight, diet, and physical activity-related beliefs and practices among pregnant and postpartum Latino women: the role of social support. Matern Child Health J. 2006:10:95-104.

26. Mickelson KD, Joseph JA. Postpartum body satisfaction and intimacy in firsttime parents. Sex Roles. 2012:67:300-10.

27. Fitzsimmons-Craft EE. Social psychological theories of disordered eating in college women: review and integration. Clin Psychol Rev. 2011:31:1224-37.

28. Berry KH. The body image of a primigravida following cesarean delivery. Health Care Women Int. 1983:4:367-76.

29. Kariman N, Tame Al, Moghaddam JZG. Association between body image and labor pain perception in primiparous and multiparous women. Pajoohandeh J. 2013;18:103-8.

\section{Publisher's Note}

Springer Nature remains neutral with regard to jurisdictional claims in published maps and institutional affiliations.

Ready to submit your research? Choose BMC and benefit from:

- fast, convenient online submission

- thorough peer review by experienced researchers in your field

- rapid publication on acceptance

- support for research data, including large and complex data types

- gold Open Access which fosters wider collaboration and increased citations

- maximum visibility for your research: over $100 \mathrm{M}$ website views per year

At $\mathrm{BMC}$, research is always in progress.

Learn more biomedcentral.com/submissions 